\title{
Why do two-thirds of Australian irrigators use no objective irrigation scheduling methods?
}

\author{
K. D. Montagu ${ }^{1} \&$ R. J. Stirzaker ${ }^{1,2}$ \\ ${ }^{1}$ Cooperative Research Centre for Irrigation Futures, \\ PO Box 56, Darling Heights, Queensland 4350, Australia \\ ${ }^{2}$ CSIRO Land and Water, PO Box 1666, ACT 2601, Australia
}

\begin{abstract}
There is significant pressure on irrigators to improve on-farm water use. A range of objective irrigation scheduling methods, such as soil monitoring, evaporation and decision support tools, have been developed to address this need. We examined how these tools have been adopted by Australian irrigators using data from an Australian Bureau of Statistics water survey of 7,280 irrigators in 2003. A total of 2.2 million hectare's were irrigated in 2002-2003 with irrigated pasture accounting for $39 \%$ of the area irrigated and $36 \%$ of the water consumed by agriculture. Cotton, grape and fruit irrigators, who account for $27 \%$ of the water used for irrigation, are the biggest users of objective scheduling methods. But still only one quarter to a third of growers are using these methods. For most irrigated crops the use of objective irrigation scheduling methods increases with farm size. The exceptions being pasture and sugar, where the use of objective irrigation scheduling methods remains low irrespective of the farm size. The major users of objective irrigation scheduling tools are where enterprise profitability is directly linked to improved crop water management, such as cotton, grape and fruit production. Other industries, particularly pasture, will lag in the use of these tools because the profitability of their enterprisers is not as sensitive to water management. Until new drivers emerge then it is unlikely that these enterprises will invest in tools to improve irrigation management. With drought and increased competition water reducing allocations, and the increased focus on river and ecosystem health, we may be seeing some of the new drivers emerge.
\end{abstract}

Keywords: objective irrigation scheduling methods, Australia, survey, soil water monitoring tools, evaporation. 


\section{Introduction}

In many countries irrigated agriculture accounts for typically $70 \%$ of the water consumed. The decision on when and how much water to apply to the crop is arguably the most important decision, in terms of both determining the fate of applied water and the financial return (Meyer and Montagu [1]). This is a decision made many times over a season by irrigators. To assist in managing the timing and amount of irrigation applied, science has provided a range of soil monitoring (e.g. Charlesworth [2]), evaporation and decision support tools (e.g. Inman-Bamber and Attard [3]) and more recently remote sensing products (e.g. Johnson et al [4]).

With many regions of the world needing to improve on-farm water management for water conservation, sustainable food production, farm profitability and environmental quality, what is the use of these tools? The limited evidence available suggests that less than one in four irrigators make use of some objective irrigation scheduling tool or service. In Washington, USA, between $18-28 \%$ of producers directly, or indirectly via consultants or extension services, utilise some form of crop evaporation data or soil moisture sensors to determine when and how much to irrigate (Leib et al [5]). In Australia, 13\% of irrigators used soil moisture monitoring products (Stirzaker [6]).

In this paper we look at what tools different irrigation sectors are using and the impacts of farm size. With less than $40 \%$ of irrigators using some form of objective irrigation scheduling tools we propose some explanations for the low uptake.

\section{Methods and materials}

Survey data was obtained from the Australian Bureau of Statistics (ABS [7]) first detailed irrigation Water Survey undertaken in November 2003. The survey was comprised of 25 questions which covered the areas of:

1. Water sources, entitlement and trade,

2. Crops irrigated and irrigation methods,

3. Storages,

4. Irrigation tools,

5. Irrigation practices and barriers to change.

This paper uses data from areas 2, 4 and 5 .

To examine changes in irrigation scheduling methods over time, earlier data from ABS Agricultural Census undertaken in 1996 and 2001 was obtained. Farm size categories varied for each irrigation sector. The actual size (ha) of farms for the very small, small, medium, large and very large, respectively, are as follows, ; pasture 0-75, 75-150, 150-250, 250-500, 500+; cotton 0-500, 500-1,000, 1,0002,000, 2000-4,000, 4,000+; cereals 0-100, 100-250, 250-500, 500-1,000, 1,000+; sugar $0-50,50-100,100-150,150-250,250+$; fruit 0-10, 10-20, 20-40, 40-80, $80+$; rice $0-250,250-500,500-1,000 ; 1,000-2,000$; grapes $0-8,8-15,15-30,30$ $80,80+$; vegetable $0-10,10-50,50-100,100-200,200+$. 


\subsection{Surveyed population}

The Water Survey was undertaken on approximately 8,000 farm establishments. Farms were selected from a previous Agricultural Survey undertaken in 2001-02 which answered yes to the question, 'Did you irrigate between 1 July 2002 and 30 June 2003?'

A response rate of $91 \%$ was achieved for the Water Survey resulting in 7,280 responses.

\section{Results}

In 2002-2003 2.2 million hectare's were irrigated in Australia. Pasture accounted for $39 \%$ of the area irrigated and $36 \%$ of the water consumed by agriculture (Table 1).

Table 1: Irrigated area and volume of water applied in 2002-2003 to the major irrigated agricultural sectors in Australia.

\begin{tabular}{|l|c|c|c|}
\hline Crop & $\begin{array}{c}\text { Area irrigated } \\
\text { ('000 ha) }\end{array}$ & $\begin{array}{c}\text { Water volume } \\
\text { applied (GL) }\end{array}$ & $\begin{array}{c}\text { \% of agriculture } \\
\text { water use }\end{array}$ \\
\hline Pasture & 872 & 3,648 & 36 \\
\hline Cotton & 234 & 1,525 & 15 \\
\hline Cereals & 478 & 1,374 & 14 \\
\hline Sugarcane & 238 & 1,293 & 13 \\
\hline Fruit & 138 & 659 & 6 \\
\hline Rice & 44 & 615 & 6 \\
\hline Grapes & 150 & 588 & 4 \\
\hline vegetables & 72 & 447 & 6 \\
\hline
\end{tabular}

Since 1996, the proportion of irrigators who use some form of soil water monitoring equipment to decide when or how much to irrigate has risen from $13 \%$ to $22 \%$ (Table 2). Evaporation values are the only other objective tool used by a reasonable proportion of growers to decide when to irrigate or how much to apply.

Most irrigators relied on their knowledge/observation to schedule irrigations. Almost half the growers surveyed, exclusively use knowledge (i.e. personal experience on the farm) or observations only to determine when and how much irrigation to apply. Approximately $40 \%$ of growers combine local knowledge with more objective measures to make their irrigation decision.

Cotton, grapes and fruit irrigators, which account for $27 \%$ of the water used for irrigation in 2002/03, are the biggest users of objective methods (Figure 1). But still only one quarter to one third of growers are using these methods. Pasture, the sector using the most water, have the lowest use of objective irrigation scheduling methods. 
Table 2: The percentage of irrigation scheduling methods used in Australian irrigation enterprises based on 1996 and 2001 Agricultural Census and the 2003 Water Survey. Data for 1996 and $2001 \mathrm{n}=28,000 ; 2003 \mathrm{n}=7,280$.

\begin{tabular}{|c|c|c|c|}
\hline Irrigation scheduling method & 1996 & 2001 & 2003 \\
\hline & $\%$ & & \\
\hline Tensiometers & \multirow{3}{*}{$13^{\mathrm{b}}$} & 8 & 9 \\
\hline Soil probes $^{\mathrm{a}}$ & & 8 & 13 \\
\hline $\begin{array}{l}\text { Government/commercial scheduling } \\
\text { service }\end{array}$ & & 2 & 3 \\
\hline Evaporation figures/graphs & \multirow{2}{*}{$14^{\mathrm{c}}$} & 7 & 10 \\
\hline Calendar/rotational scheduling & & 12 & 13 \\
\hline Knowledge/observation & 93 & 81 & 91 \\
\hline Other methods & - & 6 & 4 \\
\hline Total $^{\mathrm{d}}$ & 120 & 124 & 143 \\
\hline
\end{tabular}

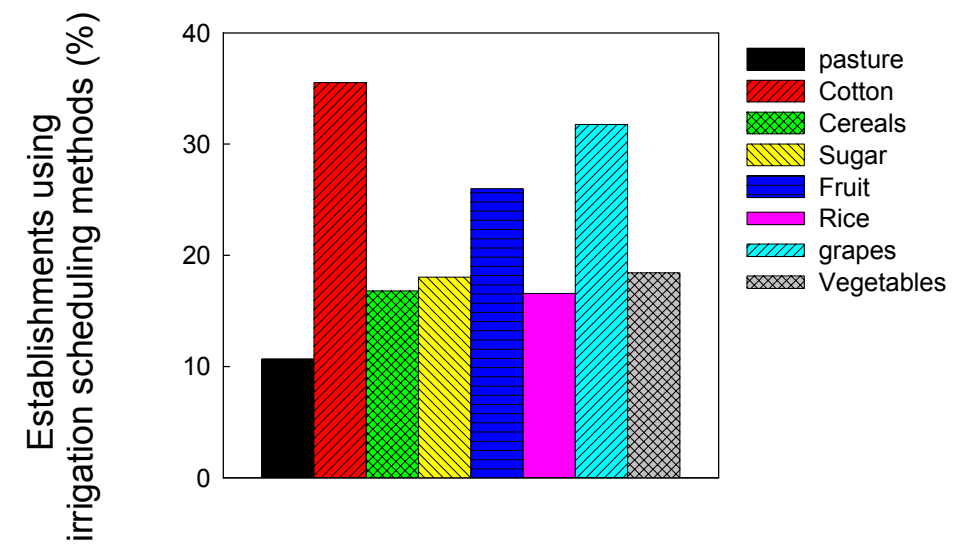

Figure 1: Proportion of irrigation establishments using objective irrigation scheduling techniques (evaporation values, tensiometers, soil probes and scheduling services). Commodities are listed in decreasing order of percentage of water consumed (Table 1). Values are maximums as some establishments maybe using two or more methods, e.g. soil probes and evaporation values). 


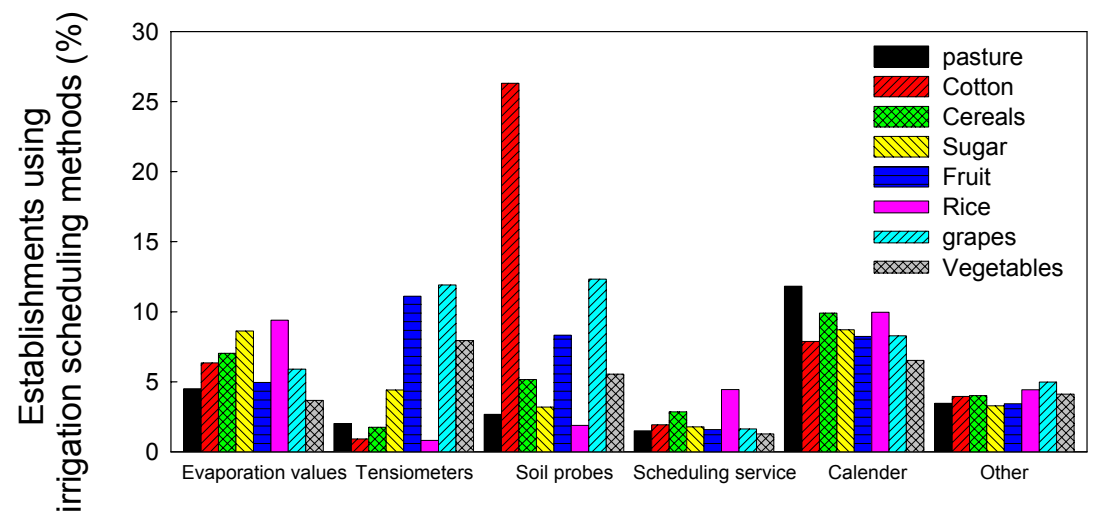

Figure 2: $\quad$ Proportion of irrigation establishments using irrigation scheduling tools. Commodities are listed in decreasing order of percentage of water consumed (Table 1). Values are maximums as some establishments maybe using two or more methods.

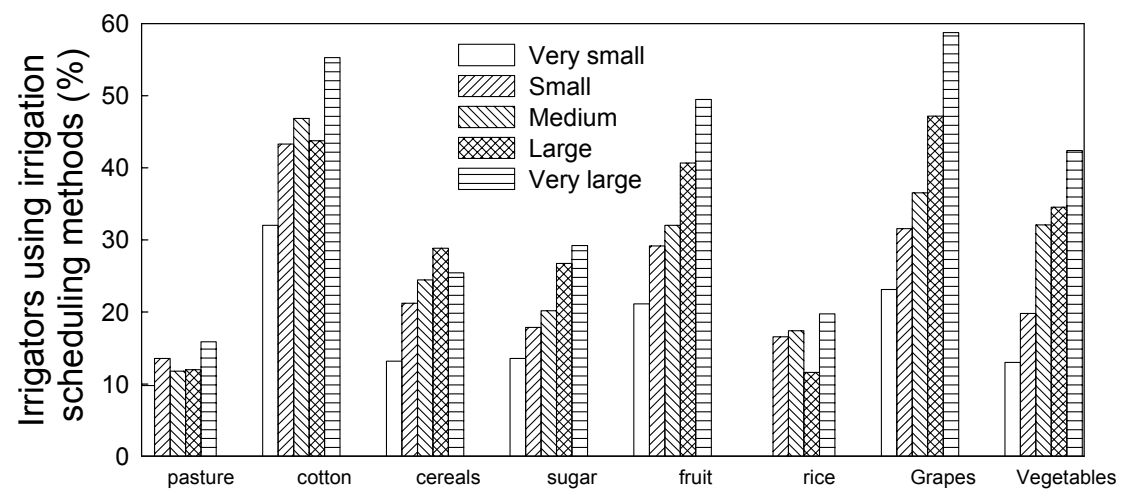

Figure 3: Impact of farm size on the proportion of irrigators using objective irrigation scheduling methods. See methods for actual farm size (ha).

Clearly, the irrigated cotton, grape and fruit sectors are leading the use of soil water monitoring tools (Figure 2). By contrast, pasture irrigators were most reliant on calendar and rotation scheduling methods. Fewer then $20 \%$ of cereal, sugar, rice, or vegetable irrigators reported using some objective method for scheduling irrigation.

In all irrigation sectors the use of objective irrigation scheduling methods increases with farm size. The exceptions being pasture and rice sugar (some trend), where the use of objective irrigation scheduling methods remains low irrespective of the farm size. 


\section{Discussion}

The survey of over 7,280 Australia irrigators clearly indicates that objective irrigation scheduling tools, such as soil water monitoring and evaporation techniques, have not captured the hearts and minds of two thirds of irrigators (Table 1). This is despite increases in the use of these techniques, particularly those using capacitance and neutron probes, which rose from 8 to $13 \%$ between 2001 and 2003 (almost all capacitance). As a result, around half of our growers base their irrigation decision solely on previous experience, observations of the soil or crop, or local irrigation practises and make no farm scale measurements.

Low adoption of the available tools can have two root causes. First, the technologies being promoted may be too expensive, risky or complex to confer a relative advantage over what the irrigator is already doing, given that water is often a small proportion of the input costs (Batz et al [8]; Stirzaker [9]; Pannel et al [10]). Second, the technologies may not be compatible with the broader goals of the farm family or farm manager, which are influenced by social, cultural and historical factors (Vanclay [11]; Kaine et al [12]; Lineham et al [13]; Pannel et al [10], Montagu et al [14]). To understand why, we need to look closer at who are using objective irrigation scheduling methods.

Let's start by looking at which irrigation sectors are using objective irrigation scheduling techniques (Figure 1). The cotton, fruit and grape sectors standout as users of objective irrigation scheduling methods. But at best only $25-35 \%$ of irrigators are using these tools. These three industries all share a common feature. Water plays a key role in determining the yield and /or quality of the crop. Mismanagement of the crops water requirements at key periods can have a major impact on profitability. In cotton, water stress during flowering will dramatically reduce yield. The yield and quality of grapes and fruit crops can be manipulated by water management to increase profitability. In these industries irrigation management has become an integral crop management tool. The need to manage water for crop production and profit has motivated leading growers to overcome many of the barriers to using these objective tools.

The pasture sector is the standout non-user of objective irrigation scheduling methods. For crops such as pasture (and lucerne), the irrigation decision has less impact on yield and profitability, compared to cotton, grapes or fruit crops. Mistiming an irrigation decision may temporarily reduce grass growth but doesn't dramatically reduce overall yield. Furthermore, the irrigated pasture industry essentially provides input into a larger production system, such as dairy or meat production. As a consequence the focus is on the animal production system, with irrigation being one input into this system. This may be the underlying reason for the low adoption of irrigation scheduling tools and the greater reliance on calendar and rotational schedules.

The vegetable sector deserves a special mention. Despite water playing a key role in determining yield and/or quality, the use of objective tools is low at less than $20 \%$. We suggest application of water far in excess of that needed by the crop effectively reduces the need to use any objective scheduling methods. For vegetable producers, water limitations are one of the easiest and cheapest 
constraints to remove. Because the value of production is very high, it is common practice to apply inputs to excess as a risk minimisation strategy Stirzaker [9]. For example, even when vegetable growers are using town water and paying over $\$ 1,000$ per $\mathrm{ML}$, there is little use of objective scheduling methods. In this situation the cost of getting it wrong is so high that the risk is mimimised by applying luxury levels and thereby ensuring that there are no yield reductions.

The bright spot in the data is that in most irrigation sectors the larger farms are make greater use of objective scheduling methods. This is most noticeable in the fruit, grape, vegetable and sugar sectors where the proportion of farms using objective scheduling methods more than doubles with increasing farm size. But despite this only around half of irrigators use some form of objective measure for scheduling irrigation.

Influence of the corporate farm sector

Looking to the future we can expect to see increased growth in the soil probe category, which is now predominantly made up of logging or manual capacitance probes. Recent data shows the adoption curve is still rising. Adoption is likely to continue as the word spreads, the technology gets cheaper and reliability and confidence in using the equipment grows among irrigators (Table 2).

There is a clear preference of irrigators to invest in new irrigation systems rather than using objective scheduling practices to optimise existing systems. Whether improvements in irrigation are realised by irrigation system upgrades without instigating monitoring has not been tested. Many farmers claim to have improved the efficiency of irrigation scheduling without investing in soil water monitoring (or other scientific methods). Here, increasing irrigation efficiency must comprise a diverse array of activities, including benchmarking activities, implementation of new equipment and on-going training.

Table 3: Percentage of irrigators who have made changes in irrigation practice, 1998-2003, and who intend to make changes in the future.

\begin{tabular}{|l|c|c|}
\hline & \multicolumn{2}{|c|}{$\begin{array}{c}\text { Percentage change in irrigation } \\
\text { practice }\end{array}$} \\
\hline & $1998-2003$ & Future \\
\hline No change & 30 & 56 \\
\hline One or more changes & 70 & 44 \\
\hline Type of change & & \\
\hline More efficient application system & 46 & 22 \\
\hline More efficient scheduling & 37 & 17 \\
\hline On-farm soil water monitoring & 15 & 9 \\
\hline
\end{tabular}




\section{Conclusion}

Industries where enterprise profitability is directly linked to improved crop water management, such as cotton, grapes and fruit, are the major users of objective irrigation scheduling tools. Other industries, particularly pasture, will lag in the use of these tools because the profitability of their enterprisers is not as sensitive to water management. Until new drivers emerge then it is unlikely that these enterprises will invest in tools to improve irrigation management. With the ongoing reductions in water allocations due to drought and increased competition for water, and the increased focus on detrimental impacts of poor irrigation management on river and ecosystem health, we may be seeing some of the new drivers emerge.

\section{References}

[1] Meyer, W. \& Montagu, K. The irrigation industry in the Murray and Murrumbidgee basins. Water, 33(5), pp. 53-56. 2006.

[2] Charlesworth, P.B. Soil Water Monitoring $2^{\text {nd }}$ edition. Irrigation Insights No. 1. Land \& Water Australia, Canberra, 2005.

[3] Inman-Bamber, G. \& Attard, S. Inventory of Australian Software Tools for On Farm Water Management. Technical Report No. 02/05. CRC for Irrigation Futures, Toowoomba, Australia. 2005.

[4] Johnson, L. Pierce, A. Michaelis, T. Scholasch, and Nemani, R. Remote Sensing and Water Balance Modeling in California Drip-Irrigated Vineyards. Proc ASCE World Environmental \& Water Resources Congress, Omaha NE, 2006.

[5] Leib, B.G., Hattendorf, M., Elliot, T., \& Matthews, G. Adoption and adoption of scientific irrigation scheduling: trends from Washington, USA as of 1998. Agricultural Water Management 55: 105-120. 2002.

[6] Stirzaker, R.J. Soil moisture monitoring: state of play and barriers to adoption. Irrigation Matters Report No. 01/06. CRC for Irrigation Futures, Toowoomba, Australia. 2006.

[7] Australian Bureau of Statistics. Water Use on Australian Farms. Commonwealth of Australia, Canberra. 2005.

[8] Batz, F.J., Peters, K.J., \& Janssen, W. The influence of technology characteristics on the rate and speed of adoption. Agricultural Economics 21: 121-130. 1999.

[9] Stirzaker, R.J. The problem of horticulture matching the biophysical efficiency with the economic efficiency. Agroforestry Systems 45: 187-202. 1999.

[10] Pannell, D.J., Marshal, G.R., Barr, N., Curtis, A., Vanclay, F., \& Wilkinson, R. Understanding and promoting adoption of conservation practices by rural landholders Australian Journal of Experimental Agriculture 46: 1407-1424. 2006. 
[11] Vanclay, F. Social principles for agricultural extension to assist in the promotion of natural resource management. Australian journal of experimental agriculture 44: 213-224. 2004.

[12] Kaine, G., Bewsell, D., Boland, A., \& Linehan, C. Using market research to understand the adoption of irrigation management strategies in the stone and pome fruit industry. Australian Journal of Experimental Agriculture 45: 1181-1187. 2005.

[13] Linehan, C.J., Krstic, M.P., \& Kaine, G. Combining Biophysical and social science to achieve change through targeted extension. ACTA Horticulturae 672: 211-216. 2005.

[14] Montagu, K., Thomas, B., Thomas, G., Christen, E., Hornbuckle, J., Baillie, C., Linehan, C., Smith, P., Gallo, F., North, S., Meyer, W., Stirzaker, R. \& Cornish, P. From Enterprise Planning to the Paddock. Irrigation Insights No. 6. Land \& Water Australia and IF Technologies Pty Ltd. 2006. 